\title{
On Determinatives and the Category-Function Distinction: A Reply to Brett Reynolds
}

\author{
Iryna Lenchuk and Amer Ahmed
}

This article examines the arguments made in the article "Determiners, Feline Marsupials, and the Category-Function Distinction: A Critique of ELT Grammars" by Brett Reynolds recently published in the TESL Canada Journal (2013). In our response, we demonstrate that the author's arguments are problematic on both theoretical and empirical grounds. In particular, we show that, by the author's own metrics, (a) the items in the so-called my set (i.e,. my, your, his/ $h e r$, etc.) should be determinatives rather than pronouns, and (b) even items that the author argues to be determinatives (i.e., all, many, few, little, etc.) cannot be classified as such if we apply the tests suggested by the author. We conclude our critical response by discussing some of the pedagogical implications of the author's article.

Cet article porte sur les arguments présentés dans l'article "Determiners, Feline Marsupials, and the Category-Function Distinction: A Critique of ELT Grammars" écrit par Brett Reynolds et récemment publié dans la Revue TESL du Canada (2013). En réponse à cet article, nous démontrons que les arguments de l'auteur sont problématiques sur les plans tant théorique qu'empirique. Plus précisément, nous expliquons, en nous basant sur les paramètres mêmes de l'auteur, que (a) les items de l'ensemble qu'il nomme 'my set' (c.-à-d., ma, ta, sa, etc.) devraient être considérés des déterminants plutôt que des pronoms et que (b) même des items que l'auteur décrit comme étant des déterminants (c.-à-d., tout, plusieurs, peu, etc.) ne peuvent être classés ainsi si l'on se base sur les tests qu'il propose. Nous concluons notre critique en discutant certaines incidences pédagogiques découlant de l'article de l'auteur.

This article is a critical analysis of "Determiners, Feline Marsupials, and the Category-Function Distinction: A Critique of ELT Grammars" by Reynolds (2013). We examine the author's claims, and demonstrate that they are not supported by theoretical or empirical evidence.

The author makes the following claims:

1. The information that can be found in ESL textbooks, dictionaries, and reference materials with regards to words such as the, this, some, many, either, each is confusing. The confusion is due to the fact that the abovementioned materials do not differentiate between the concept of a syntactic category (i.e., determinatives) and that of a syntactic function (i.e., specifier, head, modifier). Reynolds then claims that, first, words such as 
my, your, his, her, our, their do not belong to the category of determinatives; they are pronouns. Second, he claims that words such as few, little, many are determinatives rather than pronouns.

2. The author cautions that a failure to make a clear distinction between a category and a function raises serious concerns about the core values of ELT. He asks: "What does it matter that we in ELT might call my a determinative and many a pronoun, or that we hew to frameworks largely left behind by linguists?" (p. 12), and responds by saying, "One simple answer is accuracy, academic integrity, and professionalism" (p. 12).

\section{Discussion}

\section{Conceptual Problems with the Author's Proposal}

There is a conceptual problem with the author's categorization of determinatives (p. 7). Three properties generally characterize the determinative category (D): (a) D cannot combine with the or $a$ or with each other; (b) D can combine with a singular count noun to form a grammatical noun phrase (NP); (c) D can occur as a head in the partitive construction (i.e., HEAD + of + DEFINITE NP) (p. 7). Lexical items qualify as determinatives if they have one, two, or all of the three properties required (see Reynolds, 2013, Tables 1-2, pp. 8-9). ${ }^{1}$ The question immediately arises as to how to evaluate these properties. The properties do not meet the standard rigid categorization adopted in formal linguistics (see, e.g., Tallerman, 2011). ${ }^{2}$ Reynolds does not base his categorization of determinatives on any linguistic framework, as he does not cite any references when providing these properties (see p. 7). However, we can still draw some very close parallels between Reynolds and others. For example, Huddleston \& Pullum (2002, p. 539), in a section called "Criteria for determinatives," provide the following three properties of determinatives:

1. "Mutual exclusiveness with the articles." They add that "[t]his criterion admits the following items as determinatives: [31] another, much, we [as a determinative], any, neither, what [as interrogative/relative] , each, no, whatever, either, some, which, enough, that, whichever, every, this, you [as a determinative]."

Huddleston and Pullum (2002, p. 539) then add the following: "Also admitted by this criterion are the complex forms a few and a little." Interestingly, Reynolds (2013, Table 1, p. 8) has the following words: $a$, each, neither, this/ these, a few, either, no, welus, a little, enough, some, what(ever), another, every, that/ those, which(ever), any, much, the, you. Reynolds also argues that these words pass his first property of determinatives, namely, their inability to combine with $a$ or the or with each other except in coordination (p. 7). 
2. "Admissibility of count singular NPs" (Huddleston \& Pullum, 2002, p. 539). Interestingly, Reynolds (2013) also has as his second property of determinatives the fact that they "can combine with a singular count noun to form a grammatical noun phrase" (p. 7).

3. "The partitive construction." Here Huddleston and Pullum (2002, p. 539) state the following: "Words not included in [31] [i.e., the words in (a) above] that are admitted to the determinative category on the basis of this criterion are: [33] all, several, both, sufficient, certain, various, few, little, many, cardinal numerals." Reynolds (2013, p. 7) also has as his third property of determinatives the following: "They can occur as heads in the partitive construction (i.e., in NPs with the form: HEAD + of + DEFINITE NP)." Reynolds then adds the following: "Words admitted into the determinative category by this test but not already covered by the first two tests are shown in Table 2" (p. 8). Table 2 in Reynolds (p. 9) has the following words: all, many, two, three, four, etc. (the cardinal numerals), both, more/most, certain, several, few, sufficient, little, various.

The very close parallels above serve to show that Reynolds' three properties of determinatives as a syntactic category, together with the words that meet those properties, look strikingly similar to those of Huddleston and Pullum (2002, p. 539). At any rate, because Reynolds does not ground his properties of determinatives as a category in any linguistic framework, we assume that these are his own. Given that no linguistic framework of categorization is offered in Reynolds (2013), we can do nothing but speculate. For example, one way of thinking about these properties is in terms of the family resemblances approach of Ludwig Wittgenstein to word meanings (see, e.g., Kearns, 2000, pp. 13-15). However, as Reynolds does not mention this approach, we assume that this is not the approach he follows. Another way of thinking about these properties is in terms of the dynamic construal approach used to assign meanings to words in cognitive linguistics (Croft \& Cruse, 2004). However, the author does not mention that approach either. In fact, the properties above do not fit into the dynamic construal approach, in which there should be no specific distinction drawn between any two categories out of context. Applied to the present discussion, this would mean that lexical items can be pronouns in some contexts, but determinatives in others (see Cruse, 2004, pp. 262-272, on conceptual categories). However, this would be the same position held by ELT textbook writers and applied linguists, one that the author dedicates his article to argue against. Having said the above, we believe that the author's way of categorization is problematic from the perspective of the standard rigid categorization applied in formal linguistics, where each property is necessary and all properties jointly define a category (see, e.g., Tallerman, 2011, p. 36). 


\section{Empirical Problems with the Author's Proposal}

Are the words included in the my set pronouns by the author's criteria?

Reynolds (2013, pp. 9-11) argues that words belonging to the my set are pronouns, not determinatives. In this section, we apply the linguistic tests offered in Reynolds (2013) to show that the words that belong to the my set are determinatives rather than pronouns.

In the analysis of determinatives as a syntactic category and their function as a specifier, the author uses the following tests summarized in Table 1.

Table 1

Linguistic Tests Used by Reynolds (2013)

The Determinative Category Tests (see p. 7)

If $X$ is a determinative (as a category), then generally ...

1. X cannot combine with the or $a$ or with each other (except in coordination).

2. X can combine with a singular count noun to form a grammatical NP.

3. X can occur as a head in the partitive construction (i.e., HEAD + of + DEFINITE NP) (p. 7).

(The source of the tests is not identified by the author. We therefore assume that these are his.)
The Specifier Function Tests (see p. 6)

If $X$ is a specifier (as a function), then ...

1. X occurs only in NPs.

2. X typically specifies the NP as definite or indefinite.

3. If the head of an NP is a singular countable common noun, $\mathrm{X}$ (definite or indefinite) is typically obligatory.

(These tests are based on the properties identified by Huddleston and Pullum (2002, pp. 354-355), who call this function a determiner function.

The data presented below demonstrate the tests applied to the my set.

Test 1

(1) a. ${ }^{*}$ The my/your/his/her car is expensive.

b. ${ }^{*} \mathrm{~A}$ my car is fast.

c. ${ }^{*}$ My this car has been sold.

The ungrammaticality of examples $(1 \mathrm{a}-\mathrm{c})$ shows that $m y$ cannot combine with $a$ and the, or with other members of the determinatives category with the specifier function.

Test 2

(2) My car, your dress, his umbrella, her cake, our paper, their child

The grammaticality of the NPs in (2) shows that possessives can combine with a singular count noun to form a grammatical NP.

Test 3

(3) * $[\mathrm{My}]$ of [the bags] are old. 
As shown in (3), my cannot be used in a partitive construction, and therefore cannot pass the partitive test.

The above shows that the words in the my set meet two of the three properties of determinatives as a syntactic category (i.e., Property 1 and Property 2); therefore, they are determinatives.

Now consider the specifier function tests:

Test 1

(4) a. $\left[_{N P}\right.$ My/your/his/her/our/their car] is red.

b. ${ }^{*}[\mathrm{VP}$ my go]

c. ${ }^{*}[\mathrm{ADVP}$ my quickly]

d. ${ }^{*}[\mathrm{AP}$ my beautiful]

The grammaticality of example (4a) and the ungrammaticality of examples $(4 \mathrm{~b}-\mathrm{d})$ show that $m y$ functions as a specifier according to the definition of Huddleston and Pullum (2002, pp. 354-355), in that this function occurs only with NPs.

Test 2

(5) $[\mathrm{My}$ car] is red.

In example (5), my specifies the NP as definite.

Test 3

(6) *Car is expensive.

Example (6) is ungrammatical because car is a singular common noun and obligatorily requires a specifier that can make it either indefinite, or definite, as in (7).

(7) My car is expensive.

The above shows that the words in the my set meet all three properties of determinatives with the specifier function; therefore, they are determinatives.

Reynolds (2013) also argues that

the $m y$ set has a function that is never performed by determinatives.

She would object to my taking it (Huddleston \& Pullum, 2002) [no page numbers]). Uncontroversial determinatives do not appear in this construction, but genitive NPS do [emphasis added]. So we can replace my taking it with Jean's taking it or the children's taking it, but not with * the taking it, " nearly every taking it, or * no taking it. (p. 11)

Unfortunately, this is not true. There are words in Reynolds' list of determinatives (Table 1, p. 8) that appear in this construction (e.g., She would object to us/you taking it). It is interesting to note here that the author states "We/us and you are determinatives [i.e., a category] in expression[s] such as we teachers, you students; elsewhere, of course, they are pronouns [i.e., a category]" 
(p. 8). Compare this to the following statement: "It would be ridiculous and confusing to be told that a saint, clearly an NP [i.e., a category], is at the same time an adjective [i.e., a category].Yet this is analogous to what happens in ELT when it comes to determiners" (p. 6). But if we/us and you are determinatives in certain expressions, but pronouns elsewhere, then surely we/us and you are members of two categories at the same time, namely pronouns and determinatives, and Reynolds' goal of having determinatives as one category with multiple functions falls apart here. It is worth noting in this regard that such a paradox is resolved in X-bar theory, for pronouns in this framework are determiners $(\mathrm{X})$ and determiner phrases $(\mathrm{XP})$ at the same time (see, e.g., Hornstein, Nunes, \& Grohmann, 2005).

Based on the data presented above, the my set passes two of the three tests of the determinative category, and all three tests of the specifier function; given that no one property is necessary according to the author, then the my set satisfies all the properties of the determinative category and the specifier function. It is crucial for our purpose to note here that there could, in principle, be other criteria that would suggest a pronominal analysis of the my set rather than the determinative analysis that we argue for here. For example, one might say, as Reynolds (2013, p. 10) and Huddleston and Pullum (2002) do, that the my set inflects for person, number, and gender in a way similar to other pronouns (he, she, they, etc.); therefore, the words in the my set are pronouns. The point we make here is that the my set meets all the criteria of the determinatives as a category and their function as a specifier.

Are the words in Table 2 (p. 9) determinatives by the author's criteria?

The author provides a list of lexical items (Reynolds, 2013, Table 2, p. 9) that he classifies as having the determinative category and the head function on the grounds that they meet the third property of determinatives, namely the partitive test (Test 3), which says that these words can be used in the construction (HEAD + of + a definite NP). To see how this test works, consider the following examples with some of the lexical items that Reynolds lists (Table 2, p. 9) as items that pass this test:

(8) [Many/both/several/three/few] of [the children] are playing in the garden.

The example above shows that these lexical items pass the partitive construction test, as they can be used in this construction to form a grammatical sentence.

While the above is true, the property also allows the following:

(9) * $\left[\right.$ Many $/{ }^{*}$ both $/{ }^{*}$ several $/{ }^{*}$ three $/{ }^{*}$ few $]$ of [the child] is/are playing in the garden.

As the above example demonstrates, none of the above sentences is grammatical even though each of the lexical items meets the third property. Note that the source of ungrammaticality in (9) has nothing to do with a mismatch 
in subject-verb agreement. The ungrammaticality remains regardless of the form of the copular be (i.e., is/are). Instead, the source of ungrammaticality is within the NP itself, as none of the above lexical items can be used with singular count NPs.

The above example shows that the third property is not empirically supported by the evidence.

Consider now another set of examples:

(10) a. [All/ most] of [the sugar/milk/salt/pepper] is on the table.

b. $\left[{ }^{*}\right.$ Many $/{ }^{*}$ both $/{ }^{*}$ several $/{ }^{*}$ three $/{ }^{*}$ few] of [the sugar $/ \mathrm{milk} /$ salt $/$ pepper] is/are on the table.

The example in (10a) shows that all and most are grammatical in the partitive construction with a mass (or noncount) NP. However, none of the other lexical items is grammatical with a mass NP, even though they all meet the third property. This means that the property fails the empirical test and has to be reconsidered so as to allow all and most, but rule out the rest with mass NPs. It is worth noting here that in modern linguistics, it is quite natural for all and most to show a behaviour distinct from that of the others. To explain the difference, we can borrow the notion of number transparency from Huddleston and Pullum (2002, p. 349). We can say that in NPs with all and most, the number feature of the head noun in the partitive oblique percolates up to the determiners; therefore, these determiners acquire whatever number feature the head noun has. The other determiners show the mirror image of this. Thus, in NPs with few, many, several, three, it is the number feature of the determiners that percolates down to the head noun of the partitive oblique; therefore, the head noun acquires whatever number feature the determiner has.

Consider now another problem that can be illustrated with the following contrasting pair:

(11) a. [Sufficient people] arrived.

b. \#[Sufficient] of [the three people] arrived.

The example in (11a) is grammatical because sufficient selects plural heads in addition to selecting noncount heads (Huddleston \& Pullum, 2002, p. 396). The example in (11b), on the other hand, meets Reynolds' third property; yet it is semantically anomalous (hence the \# notation). The source of the anomaly has to do with the fact that words like sufficient "express imprecise quantification" (Huddleston \& Pullum, 2002, p. 396); therefore, they are incompatible with definite NPs of the precise quantification expressed in the definite NP, the three people. Something similar happens with the following example:

\#[Both] of [the three people] arrived. 
Here the NP meets Reynolds' third property; yet the example is anomalous because both denotes a set of two, and this is incompatible with the precise quantification given in the definite NP, the three people.

Yet another problem can be found with little, as can be illustrated by the following example:

(13) * [Little] of [the facts] is/are available.

The example in (13) meets Reynolds' third property of determinative heads; yet, the sentence is ungrammatical. The ungrammaticality in (13) stems from the fact that little is only compatible with singular noncount NPs (see Huddleston \& Pullum, 2002, p. 393).

In summary, the data in this section provide evidence that the properties provided by the author to test the category of determinatives are not supported empirically.

\section{Do ESL learners need to know about determinatives and specifiers?}

This section raises another question: What are the pedagogical implications of Reynolds' (2013) article? It seems that the author is not quite sure. At one point, he tells his readers that an understanding of determinatives can help explain mistakes made by the students. For example, why is it possible to say the Schramm model, Schramm's model but not *Schramm model or *the Schramm's model? He states that "[b]etter explanations and selection of examples better to exemplify categorically similar items may help students avoid or overcome such mistakes" (p. 14). However, in the next paragraph, he states that the analysis he develops is quite complex and "students need not be burdened with the type of analysis presented here" (p. 14). The answer lies in referring the students to "a list of determinatives or to a dictionary that labels them correctly" (p. 14). It is no doubt helpful for ESL learners to have access to reference materials and good grammar books. However, it is well known from research in applied linguistics (see, e.g., Cook, 2001, pp. 37-39; VanPatten, 2011) that there is a big gap between knowing about an L2 grammar and putting it to use in actual communication. In other words, explicit grammar instruction does not always lead to successful second language acquisition (for a comprehensive discussion of the role of grammar in the ESL classroom, see Ellis, 2006; Larsen-Freeman, 2003). Today's methodology tells us that teaching grammar is not only about referring learners to reference materials or about explicit teaching of grammatical rules. Rather, it is about providing "grammar instruction within a meaning-based context that takes into account what learners need to know [italics added] in order to complete communicative activities" (Centre for Canadian Language Benchmarks, 2012, p. 53). 


\section{Conclusion}

This article provides a critical review of Reynolds' article (2013). We demonstrate that the claims made by the author are not supported by theoretical or empirical evidence. To conclude, we emphasize that we welcome the following by Huddleston and Pullum (2002): (a) introducing the determinative category and determiner function (see especially pp. 354-356) and noting that the determiner function is called a specifier in other approaches (footnote 10, p. 25); (b) proposing that determinatives can be thought of as one category with various syntactic functions (p. 421); (c) introducing heads, modifiers, and determiners as functions in the internal structure of the NP (p. 421, and the discussion throughout Chapter 5, pp. 323-523); (d) aiming to bridge the gap between traditional grammar and advances in modern linguistics (p. Xv). We believe that these ideas should all be incorporated into the field of ESL.

We agree with the author that it is essential to use the tools of modern linguistics to categorize properly and to apply them to the field of second language education; it is, however, the author's version of determinatives that we reject in this article.

\section{Notes}

1. It should be noted that the determinatives presented by Reynolds in Tables 1 and 2 (2013, pp. 8-9) are almost identical to those compiled by Huddleston and Pullum (2002, pp. 356, 361). However, the author does not provide a direct reference to their lists. Throughout the article, the work of Huddleston and Pullum is cited without page referencing. This makes it difficult to refer to the cited source, especially given the fact that the book by Huddleston and Pullum is 1,764 pages long, excluding a section on further reading, references, and indices.

2. A note should be made here on the linguistic criteria (i.e., morphosyntactic, distributional, and functional) that are used in modern linguistic theory to classify words into grammatical categories. Thus, words are classified into different grammatical categories not only because "they are grammatically alike in the language system" (Reynolds, p. 4), as stated (but not clarified) by the author. Rather, they have to have similar morphosyntactic, distributional, and functional properties. For example, the word poet is categorized as a noun because (a) it can be pluralized, as in two poets (morphosyntactic property); (b) it occupies a specific syntactic position in the NP a poet, that is, it is preceded by a determiner (distribution); (c) it has a specific function in the clause, that is, it can function as the subject of a finite clause in English, as in $A$ poet won a competition (for a more detailed description of the linguistic criteria, see, e.g., Tallerman, 2011, p. 36).

\section{Acknowledgements}

We would like to thank the two anonymous reviewers for many insightful comments and suggestions on a previous draft of this article. Their suggestions have greatly improved both the form and the content of the article. We would also like to thank the participants at the 11th Annual Graduate Student Forum, Department of Languages, Literatures and Linguistics, York University, for their feedback on a previous draft of the article. Any remaining errors are our own. 


\section{The Authors}

Iryna Lenchuk is a PhD candidate in the Linguistics and Applied Linguistics program at the Department of Languages, Literatures and Linguistics at York University, Toronto, Ontario. She is also a part-time TESL instructor at the Faculty of Continuing Education and Training, Seneca College, Toronto, Ontario.

Amer Ahmed is a PhD candidate in the Linguistics and Applied Linguistics program at the Department of Languages, Literatures and Linguistics at York University, Toronto, Ontario.

\section{References}

Centre for Canadian Language Benchmarks (CCLB). (2012). Incorporating grammar in a CLBbased program. CLB support kit. Retrieved from http://www.language.ca/documents/ clb_support_kit_1.pdf

Cook, V. (2001). Second language learning and language teaching (3rd ed.). London, UK: Arnold.

Croft, W., \& Cruse, D. A. (2004). Cognitive linguistics. Cambridge, UK: Cambridge University Press.

Cruse, A. (2004). Meaning in language: An introduction to semantics and pragmatics (2nd ed.). Oxford, UK: Oxford University Press.

Ellis, R. (2006). Current issues in the teaching of grammar: An SLA perspective. TESOL Quarterly, $40(1), 83-108$.

Hornstein, N., Nunes, J., \& Grohmann, K. K. (2005). Understanding minimalism. Cambridge, UK: Cambridge University Press.

Huddleston, R., \& Pullum, G. K. (2002). The Cambridge grammar of the English language. Cambridge, UK: Cambridge University Press.

Kearns, K. (2000). Semantics. New York, NY: Palgrave Macmillan.

Larsen-Freeman, D. (2003). Teaching language: From grammar to grammaring. Boston, MA: Heinle.

Reynolds, B. (2013). Determiners, feline marsupials, and the category-function distinction: A critique of ELT grammars. TESL Canada Journal, 30(2), 1-17.

Tallerman, M. (2011). Understanding syntax (3rd ed.). London, UK: Hodder Education.

VanPatten, B. (2011). Stubborn syntax: How it resists explicit teaching and learning. In C. Sanz \& R. P. Leow (Eds.), Implicit and explicit language learning: Conditions, processes and knowledge in SLA and bilingualism (pp. 9-21). Washington, DC: Georgetown University Press. 